\title{
Habitat residence during continental life of the European eel Anguilla anguilla investigated using linear discriminant analysis applied to otolith Sr:Ca ratios
}

\author{
J. Panfili ${ }^{1, *}$, A. M. Darnaude ${ }^{2}$, Y. J. Lin ${ }^{3}$, M. Chevalley ${ }^{2}$, Y. Iizuka ${ }^{4}$, W. N. Tzeng ${ }^{3,5}$, \\ A. J. Crivelli ${ }^{6}$ \\ ${ }^{1}$ Institut de Recherche pour le Développement (IRD), UMR 5119 ECOSYM, LABEP-AO, BP 1386, 18524 Dakar, Senegal \\ ${ }^{2}$ UMR 5119 ECOSYM, CNRS-UM2-IFREMER-IRD-UM1, Université Montpellier 2, cc093, place E. Bataillon, \\ 34095 Montpellier Cedex 5, France \\ ${ }^{3}$ Institute of Fisheries Science, National Taiwan University, Taipei 10617, Taiwan, ROC \\ ${ }^{4}$ Institute of Earth Sciences, Academia Sinica, Taipei 115, Taiwan, ROC \\ ${ }^{5}$ Department of Environmental Biology and Fisheries Science, National Taiwan Ocean University, Keelung 20224, Taiwan, ROC \\ ${ }^{6}$ Station Biologique de la Tour du Valat, Le Sambuc, 13200 Arles, France
}

\begin{abstract}
European eel Anguilla anguilla migratory behaviour during continental life is still unclear due to the multiplicity of aquatic environments colonised by the species. In the Camargue area (NW Mediterranean), eel colonisation of the Fumemorte canal, a freshwater habitat that communicates only with a vast brackish ecosystem (the Vaccarès lagoon), offers a rare opportunity to test for freshwater habitat residence during continental life. To this end, both laser ablation inductively coupled plasma mass spectrometry and electron probe micro-analysis were used to measure chronological variations of strontium concentrations ( $\mathrm{Sr}: \mathrm{Ca})$ in the otoliths of 58 silver eels captured in the canal between 1997 and 2007. Comparing mean Sr:Ca ratios measured on otolith edges with the 2 analytical methods indicated that they provide comparable measurement accuracies. Linear discriminant analysis (LDA), based on the otolith $\mathrm{Sr}$ :Ca values corresponding to the initial entrance of the fish into the brackish ecosystem and their final capture in the freshwater canal, allowed successful discrimination of the 2 habitats and reconstruction of migratory history for all individuals. Six different migratory behaviours were identified. Eels that entered the freshwater canal did so either directly (67\%) or after 1 to 2 yr spent in the lagoon (33\%), with a subsequent majority of freshwater residents (55\%) until their silvering. These results indicate the value of LDA for reconstructing habitat use during continental life using Sr:Ca ratios. They confirm the occurrence of freshwater residence during continental life in European eels, even in Mediterranean continental areas where brackish environments are predominant. This observed sedentary behaviour has implications for eel population management and conservation.
\end{abstract}

KEY WORDS: Strontium:calcium ratio · Mediterranean area LA-ICPMS · EPMA · Otolith microchemistry $\cdot$ European eel $\cdot$ Anguilla anguilla

- Resale or republication not permitted without written consent of the publisher

\section{INTRODUCTION}

The European eel Anguilla anguilla (L.) is a catadromous fish, spawning in the Sargasso Sea in the central Atlantic Ocean but growing in European con- tinental aquatic ecosystems and returning to the Sargasso Sea only after reaching sexual maturity, to spawn and die (Tesch 1977). Despite the existence of many studies documenting eel movements between marine, brackish and freshwater environments (Tzeng 
et al. 1997, 2000, Tsukamoto et al. 1998, Bonhommeau et al. 2008, Bureau du Colombier et al. 2008, Aarestrup et al. 2009, Arai et al. 2009), little is known about the dominant migratory strategies during continental life in A. anguilla. After entering freshwater, European eels are assumed to be primarily resident in freshwater habitats (Laffaille et al. 2005, Lin et al. 2011), but inter-habitat migrations between fresh and brackish waters and residence in brackish waters have been observed for this species and its close relatives (Arai et al. 2004, Daverat et al. 2005, 2006, Shiao et al. 2006, Jessop et al. 2008, Chino \& Arai 2009).

Investigating Anguilla anguilla movements during continental life and its variation at both local and global scales is of paramount importance for the conservation of this endangered species (Bonhommeau et al. 2008, Belpaire et al. 2009), especially within the context of littoral habitat alteration due to anthropogenic activities and climate change. Because the abiotic and biotic conditions experienced by the eels within their continental habitats can induce strong differences in growth rate, age at maturity, sex ratio and lifetime reproductive success (Panfili \& Ximenes 1994, Jessop et al. 2004, Walsh et al. 2004, Bevacqua et al. 2006, Daverat \& Tomas 2006, Melia et al. 2006a), habitat loss during continental life can also threaten the maintenance of eel stocks in the future through a loss in reproductive success (Bonhommeau et al. 2008, Belpaire et al. 2009). In this regard, most of the investigations have focused on the continental habitats identified along the west European coasts (Daverat et al. 2005, Laffaille et al. 2005, Arai et al. 2006, Daverat \& Tomas 2006), and nothing is known about the migratory behaviour of $A$. anguilla within its Mediterranean coastland habitats.

In the Camargue area (NW Mediterranean coastland, southern France), the vast majority of the recruiting glass eels of Anguilla anguilla enters the brackish waters of the Vaccarès lagoon, which forms the major part of the complex hydrosystem of the Rhône River delta (Crivelli et al. 2008). However, a fraction enters a small freshwater waterway used for the drainage of rice-field effluents, the Fumemorte canal (Poizat et al. 1999, Acou et al. 2003), where they are thought to remain until metamorphosis into silver eels (Acou et al. 2003). This sedentary behaviour might explain the differences in life-history traits of the adult sub-population in the canal, which exhibits a greater proportion of females (81.6 versus $45.6 \%$ ), a lower growth rate (46 versus $90 \mathrm{~mm} \mathrm{yr}^{-1}$ ) and a higher maximum age (11 versus 6 yr) than eels caught in the lagoon (see also Bevacqua et al. 2006, Melia et al. 2006b). These peculiar conditions offer an opportunity to test for habitat residence during continental life in A. anguilla, by assessing the lifetime variations in the environmental salinity experienced by the adults from the freshwater canal subpopulation during their lifetime.

Fine-scale variations in the strontium:calcium ratio (Sr:Ca) were measured across the otoliths of silver eels collected within the canal, just before the start of their spawning migration. Because fish otoliths grow throughout the lifetime and their composition reflects ambient chemical composition of the surrounding water at all times, they can be used as natural tags to reconstruct fish lifetime environmental history (Campana 1999). For example, otolith Sr:Ca varies highly between marine (high values), brackish (intermediate values) and freshwater (low values) environments (Gillanders 2005). It has therefore been widely used as a proxy of salinity to investigate lifetime migrations in anguillid eels and diadromous fishes (Secor \& Rooker 2000, 2005, Tzeng et al. 2002, 2005, Gillanders 2005, Jessop et al. 2008). In our study, variations in otolith $\mathrm{Sr}$ :Ca records during continental life were analysed and interpreted using linear discriminant analysis (LDA) to allow more accurate inference of eel movements between their final capture site (the freshwater canal with low $\mathrm{Sr}: \mathrm{Ca}$ ) and the nearby lagoons (higher Sr:Ca). Although LDA has been widely used to infer habitat origin in fish based on multi-elemental otolith signatures (e.g. Gillanders \& Kingsford 2000, Brown 2006, Tanner et al. 2011), it has, to our knowledge, never been applied on a single predicting variable (here $\mathrm{Sr}: \mathrm{Ca}$ ratio). Yet its high accuracy for discriminating habitats with contrasted otolith signatures (Swearer et al. 2003, Vasconcelos et al. 2008, Leakey et al. 2009) promises to allow precise identification of past incursions into brackish waters for eels captured in freshwater habitat. It would then provide valuable information about age at settlement within freshwater habitats (e.g. habitat residence, corresponding to small-scale movements only into the freshwater habitat), and the variability in migratory behaviour for this poorly studied geographic area.

\section{MATERIALS AND METHODS}

\section{Study area}

The freshwater waterway sampled, the Fumemorte canal (Fig. 1), is located in the Camargue, a wide area of wetlands spread over the Rhône River delta. It is part of the complex hydrosystem of the Vaccarès 

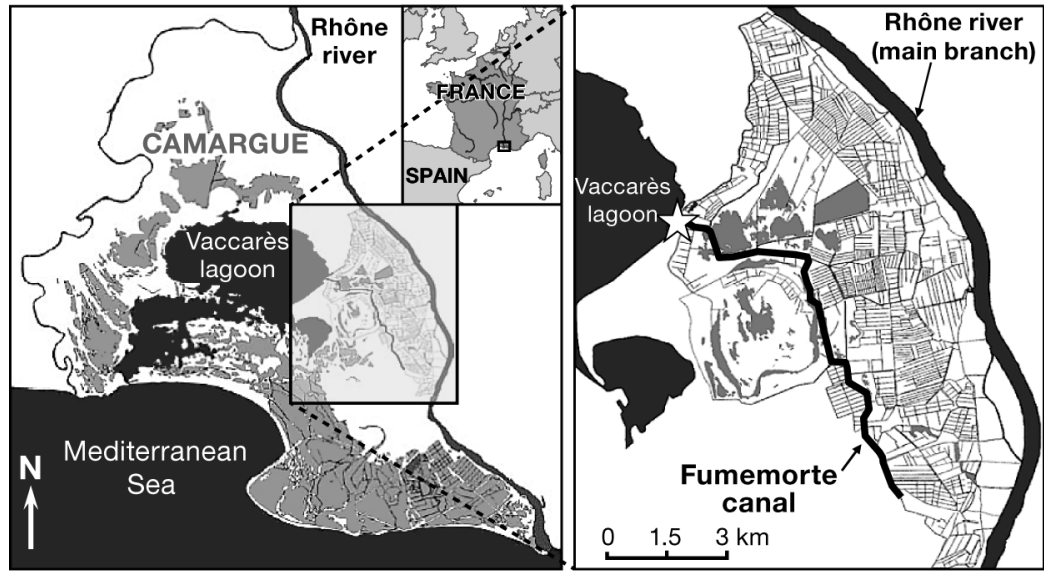

Fig. 1. Location of the Vaccarès lagoon and the Fumemorte canal within the Camargue hydro-complex (grey areas) Rhône River delta, southern France. The star indicates the sampling point at the dam (outlet of the Fumemorte canal). Only this entrance/exit allows eels to migrate between the lagoon and the freshwater canal from rice fields still flows to the Vaccarès lagoon through the Fumemorte canal. With a drainage area of $68 \mathrm{~km}^{2}$, the canal is the only freshwater supply to the lagoon (Chauvelon 1998). The canal is $14.6 \mathrm{~km}$ long and $14 \mathrm{~m}$ wide, and water depth varies between 0.5 and $2.5 \mathrm{~m}$ during the year, depending on both rainfall and rice culture effluents. At the outlet of the canal, a dam prevents the inflow of brackish water from the lagoon, whilst a fishway allows fish to move in and out (Fig. 1). Therefore, salinity varies greatly from year to year in the Vaccarès lagoon (4.8 to 28.3), but remains stable and low $(<1.4)$ in the Fumemorte canal (Fig. 2).

\section{Sampling}

lagoon, a large brackish watershed of 8800 ha that communicates with the sea only at its south-western end, through a narrow channel regulated by sluice gates. Rice culture development in the Camargue after the Second World War has led to the pumping of large quantities of freshwater from the Rhône River. Most of this water is pumped back to the river, but in the eastern part of the Vaccarès hydrosystem, water

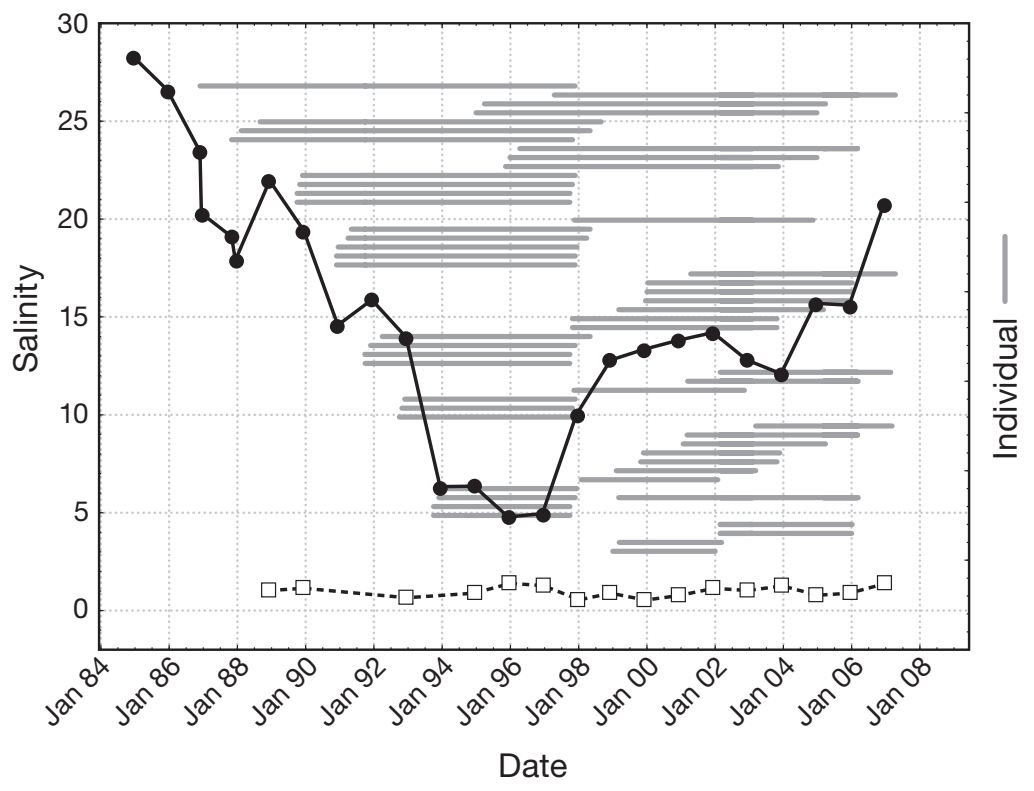

Fig. 2. Variations of annual mean salinity in the Vaccarès lagoon (solid black line) and the Fumemorte canal (dotted black line) during the time period covered by the individual life spans (grey lines) of the eels sampled in this study. In each case, the end of the grey lines indicates the date of capture, with 2 groups of individuals: those captured in 1997 to 1998 and those captured between 2001 and 2007
All fish used in this study $(\mathrm{n}=58)$ were collected between 1997 and 2007, using a $6 \mathrm{~mm}$ mesh fyke net size set at the outlet of the Fumemorte canal, just upstream of the dam (Fig. 1). This sampling strategy allowed capturing both eels entering and exiting the freshwater environment. Each year, the net was set permanently from September to December and checked weekly to collect silver eels ready to migrate back to the sea. Silvering was confirmed using multiple criteria (eye width, pectoral fin length, see EELREP 2005). All captured individuals were measured (in $\mathrm{mm}$ ) and weighed (in g). Sex was determined by visual observation of the gonads. Age was estimated by counting opaque zones in the otolith (Panfili \& Ximenes 1994, ICES 2009).

\section{Otolith preparation and $\mathrm{Sr}: \mathrm{Ca}$ measurement}

Sagittal otoliths were removed using acid-washed plastic forceps and scraped clean in ultrapure water using an acidwashed plastic toothbrush. They were photographed under a binocular microscope to allow detection of annual growth increments (opaque zones) from digitized images, following validated methods for age estimation in the European eel (Pan- 
fili \& Ximenes 1994, Melia et al. 2006a). For each fish, the 2 sagittae images were used for age estimation and verification. The otoliths were then sonicated for $5 \mathrm{~min}$, triple rinsed with ultrapure water, allowed to dry for $24 \mathrm{~h}$ under a class 100 laminar flow hood and stored in acid-washed $1.5 \mathrm{ml}$ high-density polyethylene vials.

For each fish, the right otolith was analysed for Sr:Ca composition. To allow cross validation among analytical methods, half of the otoliths for microchemical analyses $(n=28)$ were processed at the ECOSYM laboratory (France) and sampled using laser ablation inductively coupled plasma mass spectrometry (LA-ICPMS), whereas the others ( $\mathrm{n}=30$ ) were treated at the Institute of Earth Science (Taiwan) and analysed using electron probe micro-analysis (EPMA).

Otoliths for LA-ICPMS analysis were embedded individually in epoxy resin (Escil, Araldite 2020) and ground in the sagittal plane using 800, 1200 and 2400 grit SiC paper until both the core area (primordium) and the posterior edge were exposed. Resulting otolith sections were polished using diamond suspensions on lapping cloth (3 and $1 \mu \mathrm{m})$, and photographed under a light microscope to measure the distance from the otolith core to the transition mark (i.e. the ring on the otolith indicating the metamorphosis and the beginning of continental life for glass eels, Panfili \& Ximenes 1994). Otolith sections were then sonicated for $5 \mathrm{~min}$, triple rinsed with ultrapure water, allowed to dry for $24 \mathrm{~h}$ under a class 100 laminar flow hood and stored in sealed acidwashed plastic bags.

Analyses of otolith sections were conducted at the ICPMS Laboratory (UMR Géoscience) of the University of Montpellier 2, using a FINNIGAN-element XR extended Range HR-ICPMS coupled to a Compex 102 Excimer laser microprobe, with a pulse rate of $8 \mathrm{~Hz}$ and energy of $15 \mathrm{~J} \mathrm{~cm}^{-2}$. For all otoliths, a continuous transect of adjacent $26 \mu \mathrm{m}$ spots was taken on a line following the axis for maximum growth, from the outer edge of the transition mark (i.e. the start of continental life) to the posterior edge of the otolith (i.e. the date of capture in the Fumemorte canal). Otolith Sr:Ca for each spot was determined from $\mathrm{Sr}^{88}$ and $\mathrm{Ca}^{44}$ concentrations, $\mathrm{Ca}^{43}$ being the internal standard for ablation yield. Sr:Ca concentration ratios were measured as weight percent (wt\%). For each spot, $1 \mathrm{~s}$ of pre-ablation at $50 \mu \mathrm{m}$ spot size ensured decontamination of the otolith surface prior to analysis. Laser ablations occurred inside a sealed chamber with the sample gas being extracted to the HR-ICPMS in the presence of argon. Therefore, background concentrations of elements $\left(\mathrm{Sr}^{88}\right.$ and $\mathrm{Ca}^{44}$ ) within the chamber were measured for $10 \mathrm{~s}$ before each sample ablation to assess the limits of detection of the system, and then the concentrations of elements were measured during $20 \mathrm{~s}$ of ablation. The laser chamber was purged for $30 \mathrm{~s}$ to remove residual sample gas that could contaminate the next analysis. To correct for machine drift with time, a reference standard material (National Institute of Standards and Technology, NIST 610) was analysed every 10 samples. The data-reduction process included background subtraction, standardization to NIST 610 and normalization to $\mathrm{Ca}^{43}$. Analytical accuracy, based on the standard deviations of the concentrations of the NIST standard, was $100 \%$ for $\mathrm{Ca}^{44}$ and $\mathrm{Sr}^{88}$.

Otolith sections for EPMA analysis were prepared following the procedure used for LA-ICPMS, except they were coated after polishing with carbon under a high-vacuum evaporator and before analysis. Otolith $\mathrm{Sr}$ and $\mathrm{Ca}$ concentrations were measured from the outer edge of the transition mark to the edge of the otolith, as for LA-ICPMS analysis, at intervals of $10 \mu \mathrm{m}$ by an electron probe micro-analyser (JEOL JXA-8900R). Quantitative analyses were conducted using beam conditions of $15 \mathrm{kV}$ for the accelerating voltage, $3 \mathrm{nA}$ for the beam current, and a $5 \times 4 \mu \mathrm{m}$ rectangular scanning beam. X-ray intensities of $\operatorname{Sr} L \alpha$ and $\mathrm{Ca} K \alpha$ were counted by wavelength x-ray spectrometer with pentaerythritol (PET) diffraction crystals. The peak intensity of Sr $L \alpha$ was counted for $80 \mathrm{~s}$ with background measurements for $20 \mathrm{~s}$ on upper and lower sides. The peak intensity of $\mathrm{Ca} K \alpha$ was counted for $20 \mathrm{~s}$ and each background for $10 \mathrm{~s}$. Synthesized aragonite $\left(\mathrm{CaCO}_{3}\right)$ and natural strontianite $\left(\mathrm{SrCO}_{3}: \mathrm{NMNH} \mathrm{R} 10065\right)$ were used as standards to calibrate $\mathrm{Ca}$ and $\mathrm{Sr}$ concentrations in the otoliths with the Phi-Rho-Z (PRZ) software (JEOL) for data correction.

\section{Data analysis}

To allow inter-calibration of the 2 analytical tools, Sr:Ca ratios measured directly on otolith margin (i.e. the last value for each transect corresponding to the few days before fish capture in the Fumemorte canal) were used to test for potential variations in measurement precision and accuracy between LA-ICPMS ( $\mathrm{n}=28$ ) and EPMA $(\mathrm{n}=30)$. After confirmation of data normality and homoscedasticity (Shapiro and Bartlett's tests, $p>0.05)$, mean values for each of the 2 analytical tools were compared using Student's $t$-test. 
LDA was used to assign each Sr:Ca ratio from individual transects to either freshwater (FW) or brackish water (BW) habitat. LDA, also called linear discriminant function analysis (LDFA), is currently among the most commonly used methods for classifying otolith multi-elemental fingerprints (e.g. Gillanders \& Kingsford 2000, Brown 2006, Hobbs et al. 2007). Its purpose is to predict the membership of individuals to predefined classes (here, habitats) by building discriminant axes that are linear combinations of chemical elements maximizing the standard deviation between groups while minimizing it within groups. In the present work, the LDA model was built using, for each of the 58 silver eels, the first spot analysed on the otolith (i.e. the closest to the transition mark) as the Sr:Ca signature for eel residence in the BW habitat, and the last spot of analysis (i.e. that near the otolith edge), as the Sr:Ca signature for eel residence in the FW habitat. Classification accuracy of the LDA discriminant function for each habitat (BW or FW) was estimated using a cross-validation jackknife (leave-one-out) approach. Parameters of this model were then used to identify the most likely habitat (BW or FW) corresponding to the Sr:Ca value measured for each spot along the individual otolith transects. Thereby, each Sr:Ca value was independently labelled as BW or FW irrespective of its position on the transect, before the reconstruction of habitat successions along the otolith transect for all individuals and their comparison to estimate migratory behaviour variation in the eel sub-population sampled. To our knowledge, this is the first application of LDA to otolith Sr:Ca discrimination.

Finally, the differences in mean Sr:Ca values between the different migratory groups identified were tested with a 1-way ANOVA followed by post hoc Tukey tests. Statistical tests including the LDA were performed using the $\mathrm{R}$ statistical progam (R Core Development Team) and other tests were done with Statistica ${ }^{\circledR}$.

\section{RESULTS}

The 58 silver eels examined ranged in length from 41.8 to $78.0 \mathrm{~cm}$, in weight from 161 to $856 \mathrm{~g}$, and in age from 3 to 11 yr. All but 3 were females. During the time period covered by their life spans (1986 to 2007, Fig. 2), salinity remained stable, at around 1, in the Fumemorte canal while it varied greatly in the Vaccarès lagoon (between 5 and 27), with a global decrease between 1986 and 1997 and a subsequent increase between 1998 and 2007. Yet the salinity of the 2 habitats never overlapped during this period, the water of the Vaccarès lagoon always being significantly saltier (Student's $t=8.85$, df $=39$, p $<0.0001$ ) than that of the Fumemorte canal. During the whole period, the Vaccarès was then considered as a BW ecosystem, whereas the Fumemorte was clearly a FW environment.

No significant difference (Student's $t=-0.345, \mathrm{df}=$ $56, \mathrm{p}=0.731$ ) was observed between the mean otolith Sr:Ca values obtained for the Fumemorte canal with EPMA $\left([2.67 \pm 0.59] \times 10^{-3}\right)$ and LA-ICPMS $([2.72 \pm$ $0.32] \times 10^{-3}$ ), even if variability in Sr:Ca values was slightly lower with LA-ICPMS (Fig. 3). Therefore, the data gathered using the 2 analytical tools were pooled for investigation of eel migratory behaviour during continental life.

Sr:Ca ratios corresponding to eel life in the BW lagoon, i.e. at the first spot on each otolith transect (mean $[5.22 \pm 1.39] \times 10^{-3}$ ), were significantly different (Fig. 3, Student's $t=13.12, \mathrm{p}<0.0001$ ) from those corresponding to life in the FW canal, i.e. from the last spot on each otolith transect (mean [2.70 \pm 0.47$] \times$ $10^{-3}$ ). The percentage of good assignment of these spots to their actual habitat with the LDA discriminant function (jackknife cross-validation) was 100\% for FW and $83 \%$ for BW habitats, ensuring accurate discrimination between the 2 habitats and precise characterization of migration patterns during continental life for the silver eels caught in the Fumemorte canal. Lifetime variations in otolith Sr:Ca ratios were similar for the eels captured in 1997-1998 and in 2001-2007 (Fig. 4), and indicated the existence of 6 different migratory strategies irrespective of the period.
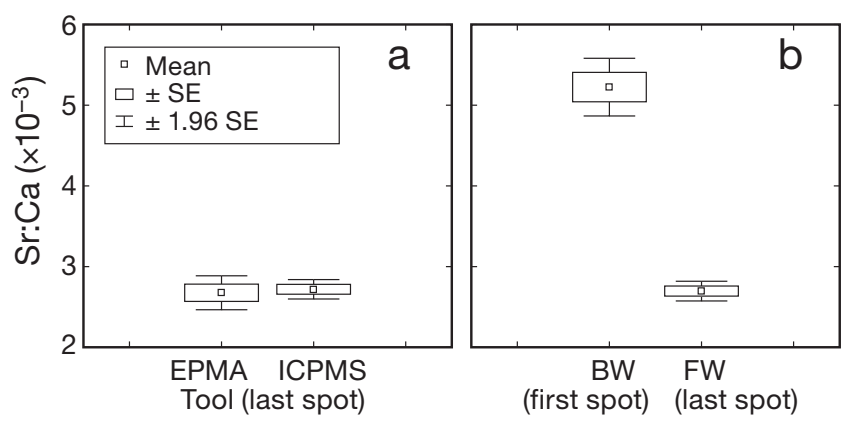

Fig. 3. Anguilla anguilla. (a) Variations in the Sr:Ca values obtained for the outer edge of the otoliths (i.e. last month of life before the capture in the Fumemorte canal) between the 2 analytical tools used in the present study: electron probe micro-analysis (EPMA; $\mathrm{n}=30$ ) and laser ablation inductively coupled plasma mass spectrometry (LA-ICPMS; $n=28$ ). (b) Variations in the Sr:Ca values obtained for the outer edge of the otoliths (last spot) corresponding to freshwater (FW, $\mathrm{n}=58$ ) and the first spot corresponding to the brackish water environment $(\mathrm{BW}, \mathrm{n}=58)$ 


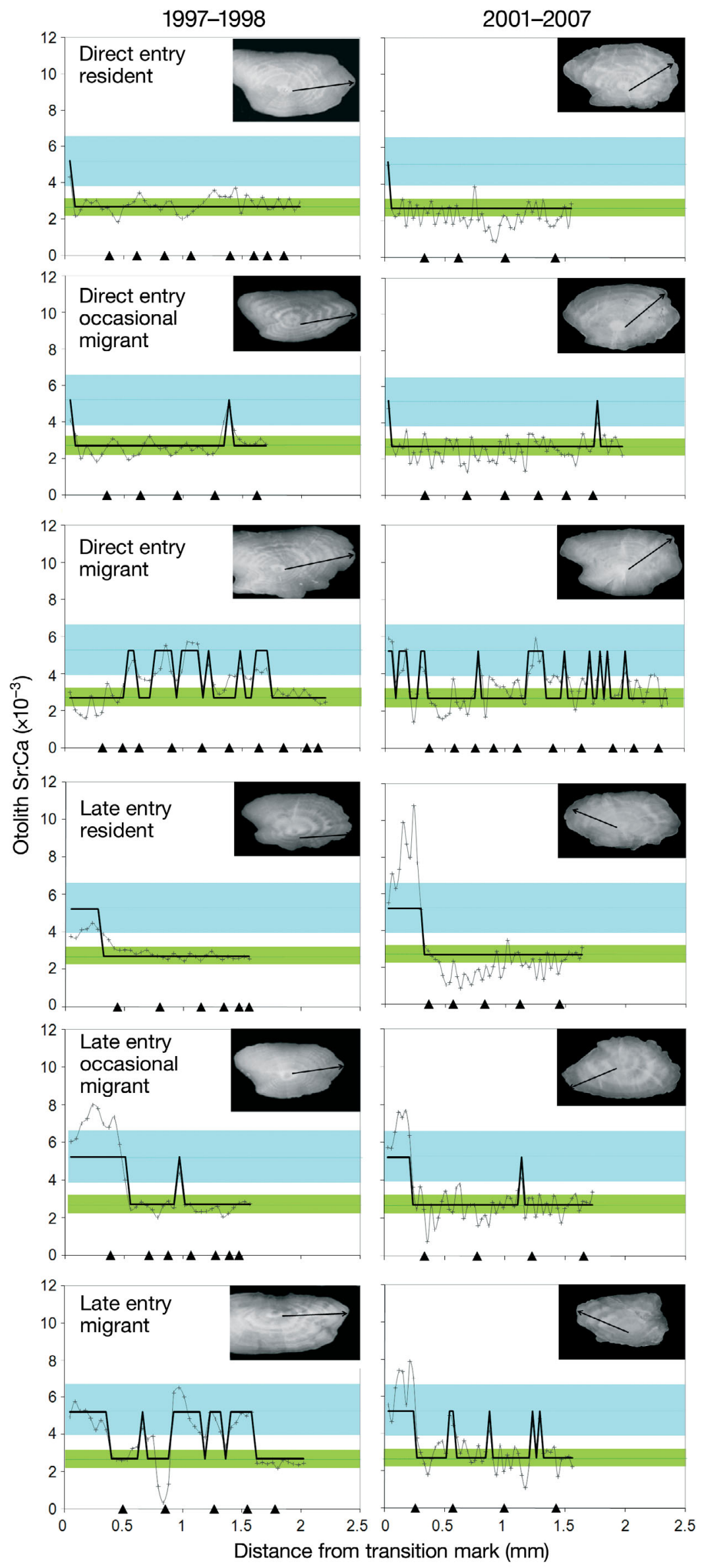

Fig. 4. Anguilla anguilla. Migration types identified from otolith $\mathrm{Sr}$ :Ca variations in Fumemorte silver eels. In each case, examples are provided from both the 1997-1998 (otolith analysis using LA-ICPMS) and the 2001-2007 (otolith analysis using EPMA) sampling campaigns. For each fish, black triangles on the $x$-axis represent the successive years of life (start of otolith annuli), and for all the Sr:Ca values measured along the analysis transect (thin line with crosses), the corresponding linear discriminant analysis assignment to either brackish water (BW) or freshwater (FW) is indicated by the thick black line. Average Sr:Ca values ( \pm SD) for BW (blue) and FW (green) are represented to help interpretation of the Sr:Ca observed patterns and assignments. Analysed individuals fell into 2 groups: those entering directly into FW and those entering after 1 or 2 yr of lagoon life. In each of these 2 groups, 3 different migration patterns were identified (FW resident, occasional migrant and migrant), resulting in 6 distinct migration types

At their arrival in continental waters, most of the individuals migrated directly to the FW canal $(67 \%)$, whereas the others $(33 \%)$ had spent no more than $2 \mathrm{yr}$ in the BW lagoon before entering the canal (Table 1). Once settled in the FW canal, eels exhibited 3 different migratory behaviours (Fig. 4). Most of them $(55 \%)$ remained permanently in the canal until their final capture (Table 1). Among the others, most (38\%) were only occasional migrants, i.e. they made only 1 short incursion in the Vaccarès lagoon during their entire continental life. As a result, only $14 \%$ of the individuals tested were regular migrants and undertook more than 1 migration (on average 4.5 migrations) between the 2 environments during their continental life. The duration of their visits to the BW lagoon was longer than that of the occasional migrants (Fig. 4), with up to 13 successive round trips occurring during the continental life (in a 9 yr old female that migrated directly into the Fumemorte canal upon its 
Table 1. Anguilla anguilla. Numbers (with percentages in parentheses) of eels classified into freshwater (FW) residents, migrants or occasional migrants in the Camargue hydro-complex as inferred by linear discriminant analysis based on otolith $\mathrm{Sr}$ :Ca ratios. Individuals are also classified depending on their direct or delayed entrance into FW. Sr:Ca means \pm $\mathrm{SD}$ are indicated for each migratory type

\begin{tabular}{|lcccc|}
\hline & $\begin{array}{c}\text { FW } \\
\text { resident }\end{array}$ & Migrant & $\begin{array}{c}\text { Occasional } \\
\text { migrant }\end{array}$ & Total \\
\hline Delayed (1-2 yr old) & $9(15)$ & $5(9)$ & $5(9)$ & $19(33)$ \\
Direct & $23(40)$ & $3(5)$ & $13(22)$ & $39(67)$ \\
Total & $32(55)$ & $8(14)$ & $18(31)$ & $58(100)$ \\
Mean Sr:Ca $\left(\times 10^{-3}\right)$ & $2.42 \pm 0.21$ & $2.66 \pm 0.20$ & $3.44 \pm 0.30$ & \\
\hline
\end{tabular}

arrival in continental waters). The timing for the initial entrance in the FW canal differed between migratory groups (Table 1), with a majority $(63 \%)$ of delayed entrance for the regular migrants, and a dominance of direct entrance in both the FW residents $(28 \%)$ and the occasional migrants $(28 \%)$. The main migratory behaviour encountered in the FW canal sub-population $(40 \%)$ was therefore a direct entrance in the canal followed by a permanent residency in this ecosystem (Table 1). Examination of individual Sr:Ca means, calculated over the whole continental life for each fish, confirmed this information (Fig. 5). Global Sr:Ca means increased regularly (Table 1 ) from the FW residents $\left([2.42 \pm 0.21] \times 10^{-3}\right)$, the occasional migrants $\left([2.66 \pm 0.21] \times 10^{-3}\right)$, to the regular migrants $\left([3.44 \pm 0.30] \times 10^{-3}\right)$. As expected, with few exceptions, SD variability in $\mathrm{Sr}$ :Ca during continental life was lowest for the resident fish $\left(\right.$ mean $=0.21 \times 10^{-3}$ ) and highest for the regular migrants (mean $=0.30 \times 10^{-3}$ ), with occasional migrants showing intermediate values. ANOVA revealed significant differences between individual means between behavioural groups $\left(F_{2,55}=68.60, \mathrm{p}<0.0001\right.$, all being different as indicated by the post hoc Tukey test, $\mathrm{p}<0.001$ ). The discrimination of migrant versus resident individuals was possible directly by using $\mathrm{Sr}$ :Ca values averaged over the whole continental life.

\section{DISCUSSION}

Precision in otolith composition measurement by available analytical tools has long been overlooked,

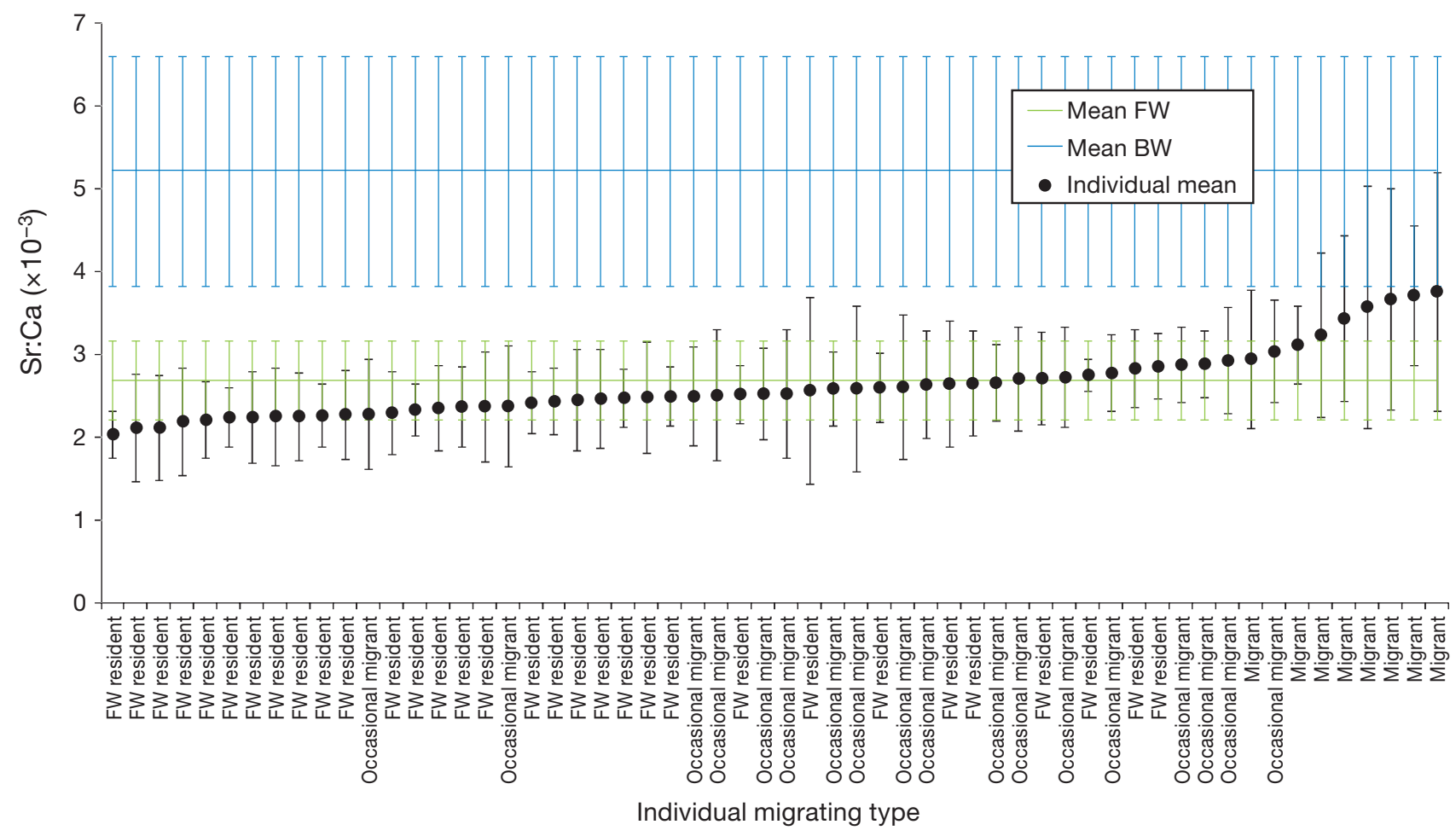

Fig. 5. Anguilla anguilla. Ranking of the individuals of each migration type (freshwater [FW] resident, occasional migrant or migrant) according to the mean $( \pm \mathrm{SD}$ ) of the Sr:Ca values measured in their otoliths after they entered the Fumemorte canal. To facilitate interpretation, average Sr:Ca $( \pm$ SD) obtained for both the brackish water (BW) and the FW habitats are represented in blue and green, respectively 
although it can be crucial when comparing the results from different studies. Otolith strontium concentrations had already been shown to be measurable with precision by LA-ICPMS and 2 other analytical techniques, viz. wavelength-dispersive electron microprobe and proton-induced X-ray emission (Campana et al. 1997). Yet these results were not derived from wild fish otoliths, in which $\mathrm{Sr}$ :Ca might be lower. The present study validates, as did Arai \& Hirata (2006), the use of both EPMA and LA-ICPMS, due to the peculiar ecological conditions encountered by Anguilla anguilla in the Camargue area. The similarity of the Sr:Ca values obtained with both methods indicated comparable measurement accuracies for the 2 analytical tools. The slightly lower variability in Sr:Ca values obtained with LA- ICPMS suggested that its precision might be higher than that of EPMA, although it could also be due to a partial smoothing of the natural variability in the otolith signal due to the slightly larger spot size with this tool.

The value of otolith Sr:Ca for reconstruction of fish individual movements between waters with different salinities is widely recognised and was the purpose of numerous applications looking at fish anadromous and catadromous migrations (e.g. Secor \& Rooker 2000, Gillanders 2005). Our results supported these findings and further stressed the exceptional capacity of otolith Sr:Ca to identify even small-scale movements involving changes in salinity during continental life, at least for the European eel.

When interpreting otolith Sr:Ca transects for any species, the main problem is to attribute a specific $\mathrm{Sr}$ :Ca value to each particular habitat. Hence, the use of $\mathrm{Sr}$ :Ca ratios determined for fish living in one environment or region for interpreting results from a different region might lead to misclassification of migratory life-history types (Jessop et al. 2007, 2008, Lin et al. 2011). The unique geographic situation encountered by Anguilla anguilla in the Camargue area constituted a case study to test for eel movements between adjacent ecosystems with close yet different salinities. Because all glass eels that arrive in the study area after their oceanic migration have to cross the entire Vaccarès lagoon before accessing the FW canal, the signatures for the first and the last spots measured on the otoliths in the present study corresponded to eel initial migration within the lagoon and to their final capture in the FW canal, respectively. This allowed accurate estimation of otolith $\mathrm{Sr}$ :Ca ratios for both environments. The $\mathrm{Sr}$ :Ca value obtained here for the BW ecosystem $([5.22 \pm 1.39] \times$ $10^{-3}$ ) is comparable to those commonly reported for this species: $(5.39 \pm 1.09) \times 10^{-3}$ in the coastal Baltic sea (Tzeng et al. 2000), $3.23 \times 10^{-3}$ in brackish Lithuanian waters (Shiao et al. 2006) and (6.73 to 8.89) $\times$ $10^{-3}$ in Irish coastal waters (Arai et al. 2006). In contrast, the Sr:Ca value found for the Fumemorte canal $\left([2.70 \pm 0.47] \times 10^{-3}\right)$ was in accordance only with that of the Turkish FW habitats $\left([2.79 \pm 1.21] \times 10^{-3}\right)$ studied by Lin et al. (2011). All other Sr:Ca values reported for $A$. anguilla in European FW environments are lower than that of the Fumemorte canal and ranged from $0.71 \times 10^{-3}$ to a maximum of $2.24 \times 10^{-3}$ (Tzeng et al. 2000, Arai et al. 2006, Shiao et al. 2006, Tabouret et al. 2010). This suggests that even limited variations in salinity (the Fumemorte canal had a salinity of around 1) could have a noticeable influence on eel otolith Sr:Ca. Salinity differences between the 2 habitats in the present study varied from year to year, with a minimum between 1994 and 1997. Nevertheless, the annual salinities of the 2 habitats never overlapped during the period of the study (1986 to 2007), which ensured the persistence of different otolith $\mathrm{Sr}$ :Ca values for the Vaccarès lagoon and the Fumemorte canal. This allowed us to develop a method based on LDA for reliable assignment of all Sr:Ca values corresponding to fish continental life in a specific environment (BW versus FW).

Most studies on eel migratory behaviour using $\mathrm{Sr}: \mathrm{Ca}$ have relied on empirical descriptions of the Sr:Ca variation only, with no statistical treatment of the signal (Tzeng et al. 1999, 2002, Arai et al. 2003, Tzeng 2003). The use of LDA for habitat assignment of otolith spots in the present work allowed us to overcome some technical issues commonly faced when using $\mathrm{Sr}: \mathrm{Ca}$ to reconstruct fish migrations between habitats with varying salinities (Jessop et al. 2007, 2008). Hence, in most empirical studies using $\mathrm{Sr}: \mathrm{Ca}$ to investigate fish movements during continental life, the frequency of migrations between FW and BW habitats was estimated from the number of transitions across a critical (intermediate) value of $\mathrm{Sr}: \mathrm{Ca}$, with a round trip comprising 2 or more contiguous $\mathrm{Sr}: \mathrm{Ca}$ values equal to or above the critical value, i.e. at minimum 1 for each inter-habitat transition (Jessop et al. 2006, 2008). The nature of single Sr:Ca values deviating from the adjacent habitat norm was considered as uncertain since they could have corresponded to technical artefacts (Tsukamoto \& Arai 2001, Jessop et al. 2006). In our case, the absence of spot misclassification during the cross-validation procedure $(100 \%$ of good re-assignment for FW in the training dataset) ensured a total discrimination of both habitats based on otolith Sr:Ca ratios. Because of the presence of the dam, which prevented the entrance of saltwater into the Fumemorte canal, it 
was therefore possible to confidently test for FW habitat residence of the silver eels caught in the canal. As analytical spot size for both LA-ICPMS and EPMA (26 and $10 \mu \mathrm{m}$, respectively) corresponded to a salinity record in eel otoliths of several days to several weeks, depending on the otolith growth rate for each individual, any singleton $\mathrm{Sr}$ :Ca value that was assigned to the BW habitat did correspond to a true incursion within this environment. Because similar percentages of resident versus occasional (or regular) migrants were found using LA-ICPMS and EPMA, the otolith record sampled by 1 single spot did not appear to differ enough between the 2 analytical tools to affect our conclusions about eel migratory strategies in the area. The proportion of residency versus occasional (or not) migratory behaviour did not depend on the analytical tool used, as they were similar between LA-ICPMS and EPMA. However, by increasing the proportion of occasional migrants and decreasing that of FW residents, the statistical treatment of the Sr:Ca signal proposed in the present study probably led to slightly different yet more accurate conclusions about eel migratory behaviour than an empirical description of $\mathrm{Sr}: \mathrm{Ca}$ variation based on Sr:Ca critical habitat transition values (Jessop et al. 2008). Therefore, the use of LDA or similar Bayesian statistical methods, as that proposed by Fablet et al. (2007), must be encouraged to better reconstruct eel migrations and habitat use during continental life from otolith Sr:Ca ratios.

Our results support the dominance of FW stable habitat residence in the European eel during continental life (Daverat \& Tomas 2006) since, upon their arrival in continental waters, most of the glass eels captured in Fumemorte migrated directly into the FW canal and remained there during their entire continental life. Yet, they showed the existence of various successful migratory strategies in Camargue. Most of the individuals captured in the Fumemorte canal had a sedentary life style (55\%), whereas $31 \%$ exhibited an occasional migratory behaviour towards brackish waters, and only $14 \%$ undertook regular migrations. Such a high level of habitat residence with a clear preference for low salinities during eel continental life has already been reported for this species (Laffaille et al. 2005, Daverat \& Tomas 2006). However, both migrations between habitats and residence in estuarine habitats seem to be more generalised in other eel species (Daverat et al. 2006), confirming a high residency in some habitats. These differences in migratory strategies could result from an adaptation of the eels to different local conditions, especially in terms of habitat availability and connec- tivity, since, in northern countries where rivers are directly connected to the sea, a vast majority of individuals are resident in FW (Arai et al. 2006). In fact, mark-recapture experiments showed that European eels may be sedentary in FW during continental life, especially in small FW catchments, yet they can also exhibit important migratory behaviour through different BW environments when various continental ecosystems are connected (Laffaille et al. 2005). The different migratory patterns can be visualised directly on the otolith when looking at the relative growth mark width, as growth is generally lower in FW habitats (Panfili \& Ximenes 1994). Nevertheless, this identification of eel ecotypes is subjective because it is linked with otolith growth pattern interpretation. Therefore, the use of LDA based on otolith $\mathrm{Sr}: \mathrm{Ca}$ dosage seems more robust for discriminating the different ecotypes within a population.

This work represents the first precise characterization of eel migratory behaviour during continental life in Camargue, and more generally in a Mediterranean coastland area. The results have direct implications in terms of local fisheries management as, although 6 recurrent types of migratory behaviours were detected in the silver eels captured in the Fumemorte canal between 1986 and 2007, more than $50 \%$ of the individuals were resident in the $\mathrm{FW}$ canal. These results still need to be confirmed by investigations of the migratory behaviours of silver eels captured in the Vaccarès lagoon. However, they suggest that, upon their arrival in Mediterranean continental waters, most individuals $(62 \%)$ that migrate toward FW habitats enter them rapidly and remain there for most of the rest of their continental lives. The proportion of individuals that migrate back to the BW habitats is limited (14\%), and even in these fish, Sr:Ca global mean values indicate a predominant residence in FW during the continental life. The high percentage of FW habitat residency found in this study confirms the existence of a FW 'ecotype' within the Camarguese eels (Panfili \& Ximenes 1994), already supported by differences in life-history traits exhibited in the adult sub-population of the canal when compared to that from the lagoon, with a greater proportion of females (81.6 versus $45.6 \%$ ), a

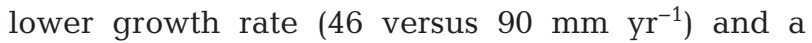
higher maximum age (11 versus $6 \mathrm{yr}$; Panfili \& Ximenes 1994, Bevacqua et al. 2006, Melia et al. 2006b).

In conclusion, the present study confirmed the predominately FW resident lifestyle of European eel populations, and also showed that after arriving from the sea, most of the elvers enter directly into the ecosystem where they will settle during their conti- 
nental life. The results of this investigation into the continental movement of European eels in the Mediterranean region are useful for the conservation management of this endangered species. The implementation of a robust LDA method based on $\mathrm{Sr}: \mathrm{Ca}$ values confidently assessed each potential habitat and allowed a precise evaluation of the percentage distribution of types of migratory life styles among the individuals, and also indicating that a high proportion of residents reach more than $10 \mathrm{yr}$ old.

Acknowledgements. We thank O. Bruguier (UMR Geosciences, Université Montpellier 2) for help with the LA-ICPMS and D. Mouillot and F. Guilhaumon (UMR ECOSYM, Université Montpellier 2) for help on the statistical approach. Y.I. acknowledges funding through Academia Sinica and the National Science Council of Taiwan (NSC 99-2116-M-001-013). We are grateful for the comments of 3 anonymous reviewers.

\section{LITERATURE CITED}

Aarestrup K, Okland F, Hansen MM, Righton D and others (2009) Oceanic spawning migration of the European eel (Anguilla anguilla). Science 325:1660

Acou A, Lefebvre F, Contournet P, Poizat G, Panfili J, Crivelli AJ (2003) Silvering of female eels (Anguilla anguilla) in two sub-populations of the Rhone Delta. Bull Fr Peche Piscic 368:55-68

Arai T, Hirata T (2006) Determination of trace elements in otoliths of chum salmon Oncorhynchus keta by laser ablation-ICP-mass spectrometry. Fish Sci 72:977-984

Arai T, Kotake A, Ohji M, Miyazaki N, Tsukamoto K (2003) Migratory history and habitat use of Japanese eel Anguilla japonica in the Sanriku Coast of Japan. Fish Sci 69:813-818

Arai $\mathrm{T}$, Kotake A, Lokman PM, Miller MJ, Tsukamoto K (2004) Evidence of different habitat use by New Zealand freshwater eels Anguilla australis and A. dieffenbachii, as revealed by otolith microchemistry. Mar Ecol Prog Ser 266:213-225

> Arai T, Kotake A, McCarthy TK (2006) Habitat use by the European eel Anguilla anguilla in Irish waters. Estuar Coast Shelf Sci 67:569-578

Arai T, Chino N, Kotake A (2009) Occurrence of estuarine and sea eels Anguilla japonica and a migrating silver eel Anguilla anguilla in the Tokyo Bay area, Japan. Fish Sci 75:1197-1203

Belpaire CGJ, Goemans G, Geeraerts C, Quataert P, Parmentier K, Hagel P, De Boer J (2009) Decreasing eel stocks: survival of the fattest? Ecol Freshw Fish 18:197-214

> Bevacqua D, Melia P, Crivelli AJ, De Leo GA, Gatto M (2006) Timing and rate of sexual maturation of the European eel in brackish and freshwater environments. J Fish Biol 69(Suppl C):200-208

Bonhommeau S, Chassot E, Planque B, Rivot E, Knap AH, Le Pape O (2008) Impact of climate on eel populations of the Northern Hemisphere. Mar Ecol Prog Ser 373:71-80

$>$ Brown JA (2006) Classification of juvenile flatfishes to estuarine and coastal habitats based on the elemental composition of otoliths. Estuar Coast Shelf Sci 66:594-611
Bureau du Colombier S, Lambert P, Bardonnet A (2008) Is feeding behaviour related to glass eel propensity to migrate? Estuar Coast Shelf Sci 80:323-329

Campana SE (1999) Chemistry and composition of fish otoliths: pathways, mechanisms and applications. Mar Ecol Prog Ser 188:263-297

Campana SE, Thorrold SR, Jones CM, Gunther D and others (1997) Comparison of accuracy, precision, and sensitivity in elemental assays of fish otoliths using the electron microprobe, proton-induced X-ray emission, and laser ablation inductively coupled plasma mass spectrometry. Can J Fish Aquat Sci 54:2068-2079

> Chauvelon P (1998) A wetland managed for agriculture as an interface between the Rhône river and the Vaccarès lagoon (Camargue, France): transfers of water and nutrients. Hydrobiologia 373/374:181-191

$>$ Chino N, Arai T (2009) Relative contribution of migratory type on the reproduction of migrating silver eels, Anguilla japonica, collected off Shikoku Island, Japan. Mar Biol 156:661-668

Crivelli AJ, Auphan N, Chauvelon P, Sandoz A, Menella JY, Poizat G (2008) Glass eel recruitment, Anguilla anguilla (L.), in a Mediterranean lagoon assessed by a glass eel trap: factors explaining the catches. Hydrobiologia 602: 79-86

> Daverat F, Tomas J (2006) Tactics and demographic attributes in the European eel Anguilla anguilla in the Gironde watershed, SW France. Mar Ecol Prog Ser 307:247-257

Daverat F, Tomás J, Lahaye M, Palmer M, Elie P (2005) Tracking continental habitat shifts of eels using otolith $\mathrm{Sr} / \mathrm{Ca}$ ratios: validation and application to the coastal, estuarine and riverine eels of the Gironde-Garonne-Dordogne watershed. Mar Freshw Res 56:619-627

Daverat F, Limburg KE, Thibault I, Shiao JC and others (2006) Phenotypic plasticity of habitat use by three temperate eel species, Anguilla anguilla, A. japonica and A. rostrata. Mar Ecol Prog Ser 308:231-241

EELREP (2005) Estimation of the reproduction capacity of European eel. Final Report. Report No. Q5RS-200101836. European Union, Brussels

Fablet R, Daverat F, De Pontual H (2007) Unsupervised Bayesian reconstruction of individual life histories from otolith signatures: case study of $\mathrm{Sr}: \mathrm{Ca}$ transects of European eel (Anguilla anguilla) otoliths. Can J Fish Aquat Sci 64:152-165

Gillanders BM (2005) Otolith chemistry to determine movements of diadromous and freshwater fish. Aquat Living Resour 18:291-300

Gillanders BM, Kingsford MJ (2000) Elemental fingerprints of otoliths of fish may distinguish estuarine 'nursery' habitats. Mar Ecol Prog Ser 201:273-286

> Hobbs JA, Bennett WA, Burton J, Gras M (2007) Classification of larval and adult delta smelt to nursery areas by use of trace elemental fingerprinting. Trans Am Fish Soc 136:518-527

ICES (International Council for the Exploration of the Sea) (2009) Report of the workshop on the age reading of European and American eel (WKAREA), 20-24 April, Bordeaux, France. ICES CM 2009\ACOM 48. ICES, Copenhagen

> Jessop BM, Shiao JC, Iizuka Y, Tzeng WN (2004) Variation in the annual growth, by sex and migration history, of silver American eels Anguilla rostrata. Mar Ecol Prog Ser 272:231-244

> Jessop BM, Shiao JC, Iizuka Y, Tzeng WN (2006) Migration 
of juvenile American eels Anguilla rostrata between freshwater and estuary, as revealed by otolith microchemistry. Mar Ecol Prog Ser 310:219-233

> Jessop BM, Shiao JC, Iizuka Y, Tzeng WN (2007) Effects of inter-habitat migration on the evaluation of growth rate and habitat residence of American eels Anguilla rostrata. Mar Ecol Prog Ser 342:255-263

> Jessop BM, Cairns DK, Thibault I, Tzeng WN (2008) Life history of American eel Anguilla rostrata: new insights from otolith microchemistry. Aquat Biol 1:205-216

Laffaille P, Acou A, Guillouet J (2005) The yellow European eel (Anguilla anguilla L.) may adopt a sedentary lifestyle in inland freshwaters. Ecol Freshw Fish 14:191-196

Leakey CDB, Attrill MJ, Fitzsimons MF (2009) Multi-element otolith chemistry of juvenile sole (Solea solea), whiting (Merlangius merlangus) and European seabass (Dicentrarchus labrax) in the Thames Estuary and adjacent coastal regions. J Sea Res 61:268-274

Lin YJ, Yalçin-Özdilek S, Iizuka Y, Gümü A, Tzeng WN (2011) Migratory life history of European eel Anguilla anguilla from freshwater regions of the River Asi, southern Turkey and their high otolith Sr:Ca ratios. J Fish Biol 78:860-868

Melia P, Bevacqua D, Crivelli AJ, De Leo GA, Panfili J, Gatto M (2006a) Age and growth of Anguilla anguilla in the Camargue lagoons. J Fish Biol 68:876-890

Melia P, Bevacqua D, Crivelli AJ, Panfili J, De Leo GA, Gatto $M$ (2006b) Sex differentiation of the European eel in brackish and freshwater environments: a comparative analysis. J Fish Biol 69:1228-1235

Panfili J, Ximenes MC (1994) Age and growth estimation of European eel (Anguilla anguilla L.) in continental waters: methodologies, validation, application in Mediterranean area and comparisons in Europe. Bull Fr Peche Piscic 335:43-66 (in French with English abstract)

> Poizat G, Chauvelon P, Rosecchi E, Crivelli AJ (1999) Passage of Rhone River fish through irrigation pumps in the Camargue: first results. Bull Fr Peche Piscicult 352:31-43 (in French with English abstract)

Secor DH, Rooker JR (2000) Is otolith strontium a useful scalar of life cycles in estuarine fishes? Fish Res 46: 359-371

Secor H, Rooker JR (2005) Connectivity in the life histories of fishes that use estuaries. Estuar Coast Shelf Sci 64:1-3

Shiao JC, Lozys L, Iizuka Y, Tzeng WN (2006) Migratory patterns and contribution of stocking to the population of European eel in Lithuanian waters as indicated by otolith Sr:Ca ratios. J Fish Biol 69:749-769

Swearer SE, Forrester GE, Steele MA, Brooks AJ, Lea DW (2003) Spatio-temporal and interspecific variation in oto-

Editorial responsibility: Christine Paetzold, Oldendorf/Luhe, Germany lith trace-elemental fingerprints in a temperate estuarine fish assemblage. Estuar Coast Shelf Sci 56:1111-1123

Tabouret H, Bareille G, Claverie F, Pecheyran C, Prouzet P, Donard OFX (2010) Simultaneous use of strontium:calcium and barium:calcium ratios in otoliths as markers of habitat: application to the European eel (Anguilla anguilla) in the Adour basin, South West France. Mar Environ Res 70:35-45

Tanner SE, Vasconcelos RP, Reis-Santos P, Cabral HN, Thorrold SR (2011) Spatial and ontogenetic variability in the chemical composition of juvenile common sole (Solea solea) otoliths. Estuar Coast Shelf Sci 91:150-157

Tesch FW (1977) The eel. Biology and management of anguillid eels. Chapman \& Hall, London

Tsukamoto K, Arai T (2001) Facultative catadromy of the eel Anguilla japonica between freshwater and seawater habitats. Mar Ecol Prog Ser 220:265-276

> Tsukamoto K, Nakai I, Tesch WV (1998) Do all freshwater eels migrate? Nature 396:635-636

Tzeng WN (2003) The processes of onshore migration of the Japanese eel Anguilla japonica as revealed by otolith microstructure. In: Aida K, Tsukamoto K, Yamauchi K (eds) Eel biology. Springer-Verlag Tokyo, Tokyo, p 181-190

Tzeng WN, Severin KP, Wickstrom H (1997) Use of otolith microchemistry to investigate the environmental history of European eel Anguilla anguilla. Mar Ecol Prog Ser 149:73-81

Tzeng WN, Severin KP, Wickstrom H, Wang CH (1999) Strontium bands in relation to age marks in otoliths of European eel Anguilla anguilla. Zool Stud 38:452-457

> Tzeng WN, Wang CH, Wickstrom H, Reizenstein M (2000) Occurrence of the semi-catadromous European eel Anguilla anguilla in the Baltic Sea. Mar Biol 137:93-98

> Tzeng WN, Shiao JC, lizuka Y (2002) Use of otolith Sr:Ca ratios to study the riverine migratory behaviors of Japanese eel Anguilla japonica. Mar Ecol Prog Ser 245:213-221

> Tzeng WN, Severin KP, Wang CH, Wickstrom H (2005) Elemental composition of otoliths as a discriminator of life stage and growth habitat of the European eel, Anguilla anguilla. Mar Freshw Res 56:629-635

> Vasconcelos RP, Reis-Santos P, Tanner S, Maia A and others (2008) Evidence of estuarine nursery origin of five coastal fish species along the Portuguese coast through otolith elemental fingerprints. Estuar Coast Shelf Sci 79: 317-327

Walsh CT, Pease BC, Booth DJ (2004) Variation in the sex ratio, size and age of longfinned eels within and among coastal catchments of southeastern Australia. J Fish Biol 64:1297-1312

Submitted: July 22, 2011; Accepted: February 13, 2012 Proofs received from author(s): April 30, 2012 